\title{
Commentary Cyclins in breast cancer: too much of a good thing Greg H Enders
}

Penn/GI Division, Philadelphia, Pennsylvania, USA

Correspondence: Greg H Enders, MD, PhD, Penn/GI Division, Suite 600/CRB, 415 Curie Boulevard, Philadelphia, PA 19104-6144, USA. Tel: +1 215898 0159; fax: +1 215573 2024; e-mail: endersgh@mail.med.upenn.edu

\begin{abstract}
Cyclin E, a key mediator of entry into the cell division cycle, is expressed abundantly in many breast cancers. However, amplification of the cognate gene is observed rarely, leaving the responsible mechanism(s) and its importance in tumorigenesis in doubt. In a recent report, Steve Reed's lab demonstrates that hCdc4/Fbw7 targets cyclin E for ubiquitin-mediated proteolysis and is mutant in a breast cancer cell line with high cyclin E levels. Independent work demonstrates that a Drosophila hCdc4 homologue constrains cyclin E expression in vivo. These results suggest that lesions in protein degradation pathways may contribute to cyclin $\mathrm{E}$ deregulation in breast cancer.
\end{abstract}

Keywords: breast cancer, Cdc4, cyclin, proteolysis

\section{Introduction}

The discovery that cyclin-dependent kinases (Cdks) orchestrate key cell-cycle transitions in all eucaryotes [1] was recognized by the 2001 Nobel Prize in Physiology or Medicine, awarded to Leland Hartwell, Paul Nurse, and Tim Hunt. The defining feature of the cyclins is that their abundance fluctuates during the cell cycle, modulating Cdk activity and driving cell-cycle progression. Important information continues to emerge on the role of cyclins in breast cancer. Shortly after their identification in mammals, it was found that cyclin genes were overexpressed and amplified in a fraction of breast cancers, providing the first evidence that cyclin deregulation, in particular increased transcription, may promote this disease [2].

The present commentary focuses on a recent publication from Steve Reed's laboratory that implicates defective cyclin proteolysis as an alternative mechanism of cyclin overexpression in breast cancer [3].
Evidence for involvement of cyclin $D$ in breast cancer has been particularly strong. Cyclin $D$ gene amplification was readily detected in breast cancers [4]. Moreover, cyclin D1 overexpression in breast epithelium predisposes to neoplasia in transgenic mice [5]. Conversely, germline deletion of cyclin D1 prevents normal proliferation of the breast epithelium during lactation $[6,7]$ and protects against breast neoplasia [8].

What about cyclin $E$, the other major class of cyclins that promote entry into the mammalian cell cycle? In vitro experiments have demonstrated that cyclin E overexpression can mediate genetic instability as well, a factor that can accelerate tumorigenesis [9]. Transgenic experiments in the mouse have confirmed that cyclin $\mathrm{E}$ overexpression can induce mammary gland hyperplasia and cancer [10].

In comparison with normal human breast tissues and cultured cells, many human breast cancers display high-level

Ago = Archipelago; Cdk = cyclin-dependent kinase; hCdc4 = human protein homologous to Saccharomyces cerevisiae cell division cycle mutant 4 ; $\mathrm{SCF}=$ Skp1/Cul1/F-box. 
expression of cyclin $\mathrm{E}$ but also elevations in other markers of cell proliferation, such as Ki67 $[2,11]$. In these tumors, it is difficult to distinguish whether the observed cyclin E expression is a primary or secondary event in cell proliferation. In other tumors, cyclin E expression is high relative to the proliferative index of the tumor, more suggestive of primary cyclin deregulation [11]. The notion that cyclin E overexpression plays a significant role in breast cancer is further supported by evidence that high expression levels detected by immunohistochemistry in primary tumors predict poor outcomes [12]. Nonetheless, amplification of cyclin $E$ genes has been found only rarely in breast cancers, leaving the mechanism(s) and specificity of the observed cyclin E expression in doubt [4].

\section{Dissecting cyclin E regulation in yeast}

Previous work by the Reed laboratory and others revealed that cyclin $\mathrm{E}$ degradation is fostered by Cdk phosphorylation on a threonine residue at position 380 of the primary sequence $[13,14]$. Even though yeast do not possess a true cyclin $\mathrm{E}$ homolog, degradation of human cyclin $\mathrm{E}$ in yeast is also fostered by Cdk phosphorylation on Thr380, consistent with the remarkable conservation of key cellcycle paradigms and proteins across eucaryotes.

Strohmaier et al. took advantage of the facile genetic analyses that can be performed in yeast to identify proteins involved in cyclin E degradation. Their results implicated Skp1/Cul1/F-box (SCF) complexes and, in particular, the substrate targeting protein Cdc4 in cyclin E proteolysis in yeast. SCF complexes are well-known mediators of protein degradation, directing specific substrates to the $26 \mathrm{~S}$ proteosome by addition of chains of ubiquitin, a small protein added covalently to lysine residues on the target [15-17]. A second phosphorylation on cyclin E, at Thr62, was shown to facilitate cyclin $\mathrm{E}$ degradation. The use of dual phosphorylation sites is consistent with recent evidence that efficient recognition by $\mathrm{Cdc} 4$ can be spurred by multisite phosphorylation of target proteins [18]. Furthermore, the sequences surrounding Thr380 and Thr62 are good matches to the loose consensus sequence for Cdc4 binding defined in an independent study [14].

Strohmaier et al. then identified in Genbank a human expressed sequence encoding a protein homologous to Cdc4 (hCdc4) [3]. The hCdc4 cDNA was shown to partially rescue the cdc4 phenotype in yeast. hCdc4 was found to bind cyclin E, in a manner facilitated by phosphorylation of the latter protein. Overexpression of hCdc4 in human cells reduced the half-life of cyclin E. Conversely, overexpression of a mutant hCdc4 extended the cyclin $\mathrm{E}$ half-life. Finally, hCdc4 immunoprecipitates could mediate ubiquitination of cyclin $\mathrm{E}$ in a cell-free extract.

Similar results were reported in an elegant study by termed SCFFbw7. This nomenclature highlights the presence in the primary sequence of an 'F-box', which marks the protein as a specificity factor for SCF complexes, and a WD (tryptophan-aspartic acid) repeat, a motif implicated in protein recognition $[20,21]$.

The Reed group then tested the notion that mutations in hCdc4 might contribute to upregulation of cyclin $E$ in breast cancer. Of eight randomly chosen breast cancer cell lines, two showed high levels of cyclin $E$ protein without a corresponding elevation in cyclin E mRNA, by comparison with an immortalized line derived from normal breast. hCdc4 mRNA from one of the two malignant cell lines, SUM149PT, migrated aberrantly through an agarose gel. Immunoreactive hCdc4 could not be detected in this cell line, and the cyclin E half-life was extended in comparison with that observed in the normal breast cell line. The hCdc4 mRNA from SUM149PT cells was sequenced, revealing a truncating mutation. Southern blotting confirmed loss of the normal hCdc4 allele.

These data are thus consistent with the notion that hCdc4 may have suppressed the growth of the SUM149PT cell of origin, providing a selective advantage to cells that inactivated both hCdc4 alleles. The other breast cancer cell line with high levels of cyclin $E$ protein relative to its mRNA presumably may harbor another defect in cyclin $\mathrm{E}$ degradation.

Whether hCdc4 inactivation in the SUM149PT cell line occurred during growth of the tumor in vivo or during establishment of the cell line remains obscure. However, compelling evidence that loss of $\mathrm{Cdc} 4$ can spur cell proliferation in vivo comes from the companion paper [22]. A mutation in a homologous Drosophila gene, dubbed Archipelago (Ago), was identified in a screen for mutations that induced hyperproliferation in the retina. Consistent with the yeast and human cell data, Ago mutants displayed elevated cyclin E levels and the mutant Ago proteins showed reduced affinity for cyclin $\mathrm{E}$ in vitro.

Cdc4 has been implicated in the degradation of several targets in yeast [17]. Hence, whether upregulation of cyclin $\mathrm{E}$ underlies the increased proliferation in Ago mutants cannot be known for certain from these data. Genetic crosses to mutants with reduced cyclin E expression, however, ameliorated the retinal phenotype of Ago mutants, consistent with the notion that cyclin $\mathrm{E}$ is a key target [22]. Three of 10 ovarian cancer cell lines examined in this study were found to have mutations in the human Ago homolog (identical to hCd4/SCFFbw7). On the contrary, no mutations were found in this gene in 17 breast cancer cell lines and in nine primary breast tumors. One ovarian cell line is homozygous for an early truncating mutation and very probably is null for hCdc4 function. The other two mutations in the ovarian cell lines were hetero- 
zygous missense (single amino acid substitution) mutations, leaving doubt as to whether they inactivated hCdc4 function. However, both mutations alter residues identified independently as being critical for cyclin E binding [19]. Moreover, Drosophila expressing dacapo, an inhibitor of cyclin E-associated kinase activity, in the retina displayed greater retinal cell proliferation when simultaneously heterozygous for Ago. This implies that Cdc4 function may be haploinsufficient (limiting in the heterozygous state), at least in some settings.

These studies thus provide convincing evidence that Cdc4 is a rate-limiting mediator of cyclin $\mathrm{E}$ degradation. Moreover, mutations in Cdc4 can confer enhanced cell proliferation in Drosophila and are found in a fraction of ovarian and breast cancer cell lines. These findings have built a strong provisional case that hCdc4 is a tumor suppressor protein. Definitive evidence would be in hand if restoration of wildtype $\mathrm{hCdc} 4$ in cell lines that harbor hCdc4 mutations inhibits their proliferation and tumorigenicity, if $\mathrm{hCdc} 4$ mutations are identified in primary tumors and/or human familial cancer pedigrees, and if mice with engineered Cdc4 mutations are prone to tumor formation.

\section{Conclusion}

Part of the complexity of understanding cell-cycle deregulation in cancer has been the observation that specific abnormalities, such as cyclin gene amplification, have been found in only a fraction of tumors of a particular type. In some cases, this complexity has given way to simplicity with the realization that certain key cell-cycle pathways are essentially uniformly deregulated in some cancer types, but by alternative mechanisms (see [23]).

Strohmaier et al. provide strong evidence that abrogation of hCdc4-mediated degradation of cyclin $\mathrm{E}$, and perhaps other targets, contributes to development of some breast cancers, underscoring the important role played by $\mathrm{Cdk}$ deregulation in this tumor type. One lesson thus emerging from the work by Strohmaier et al. is that, although disruption of cyclin degradation may be present in only a small fraction of breast tumors, deregulation of Cdk activity (or a critical target of Cdks) may yet prove essential for breast tumorigenesis. Inactivation of retinoblastoma family proteins, mediated by both cyclin D and cyclin E, might be the common denominator [1].

Further work will establish definitively whether hCdc4 is indeed a tumor suppressor and whether cyclin E overexpression contributes to neoplasia primarily by accelerating $S$ phase entry per se, by engendering genetic instability, and/or by other mechanisms (see [24]). If cyclin E overexpression remains critical for growth of established tumors, then cyclin $E$ function may be a good target for chemotherapeutic drug development. Efforts to develop such drugs are ongoing [25].

\section{References}

1. Sherr CJ: Cancer Cell Cycles. Science 1996, 274:1672-1677.

2. Keyomarsi K, Pardee AB: Redundant cyclin overexpression and gene amplification in breast cancer cells. Proc Natl Acad Sci USA 1993, 90:1112-1116.

3. Strohmaier $\mathrm{H}$, Spruck $\mathrm{CH}$, Kaiser $\mathrm{P}$, Won KA, Sangfelt $\mathrm{O}$, Reed SI: Human F-box protein hCdc4 targets cyclin E for proteolysis and is mutated in a breast cancer cell line. Nature 2001, 413:316-322.

4. Courjal F, Louason G, Speiser P, Katsaros D, Zeillinger R, Theillet C: Cyclin gene amplification and overexpression in breast and ovarian cancers: evidence for the selection of cyclin D1 in breast and cyclin $\mathrm{E}$ in ovarian tumors. Int J Cancer 1996, 69:247-253.

5. Wang TC, Cardiff RD, Zukerberg L, Lees E, Arnold A, Schmidt EV: Mammary hyperplasia and carcinoma in MMTV-cyclin D1 transgenic mice. Nature 1994, 369:669-671.

6. Sicinski P, Donaher JL, Parker SB, Li T, Fazeli A, Gardner H, Hasla, SZ, Bronson RT, Elledge S, Weinberg RA: Cyclin D1 provides a link between development and oncogenesis in the retina and breast. Cell 1995, 82:621-630.

7. Fantl V, Stamp G, Andrews A, Rosewell I, Dickson C: Mice lacking cyclin D1 are small and show defects in eye and mammary gland development. Genes Dev 1995, 9:2364-2372.

8. $Y u$ Q, Geng Y, Sicinski P: Specific protection against breast cancers by cyclin D1 ablation. Nature 2001, 411:1017-1021.

9. Spruck $\mathrm{CH}$, Won KA, Reed SI: Deregulated cyclin E induces chromosome instability. Nature 1999, 401:297-300.

10. Bortne, DM, Rosenberg MP: Induction of mammary gland hyperplasia and carcinomas in transgenic mice expressing human cyclin E. Mol Cell Biol 1997, 17: 453-459.

11. Dutta A, Chandra R, Leiter LM, Lester S: Cyclins as markers of tumor proliferation: immunocytochemical studies in breast cancer. Proc Natl Acad Sci USA 1995, 92:5386-5390.

12. Porter PL, Malone KE, Heagerty PJ, Alexander GM, Gatti LA, Firpo EJ, Daling JR, Roberts JM: Expression of cell-cycle regulators p27Kip1 and cyclin $\mathrm{E}$, alone and in combination, correlate with survival in young breast cancer patients. Nat Med 1997, 3:222-225.

13. Won KA, Reed SI: Activation of cyclin E/CDK2 is coupled to site-specific autophosphorylation and ubiquitin-dependent degradation of cyclin E. EMBO J 1996, 15:4182-4193.

14. Clurman BE, Sheaff RJ, Thress K, Groudine M, Roberts JM: Turnover of cyclin $E$ by the ubiquitin-proteasome pathway is regulated by cdk2 binding and cyclin phosphorylation. Genes Dev 1996, 10:1979-1990.

15. Bai C, Sen P, Hofmann K, Ma L, Goebl M, Harper JW, Elledge SJ: SKP1 connects cell cycle regulators to the ubiquitin proteolysis machinery through a novel motif, the F-box. Cell 1996, 86: 263-274.

16. DeSalle LM, Pagano M: Regulation of the $\mathbf{G} 1$ to $\mathbf{S}$ transition by the ubiquitin pathway. FEBS Lett 2001, 490:179-189.

17. Tyers $M$, Jorgensen P: Proteolysis and the cell cycle: with this RING I do thee destroy. Curr Opin Genet Dev 2000, 10:54-64.

18. Nash P, Tang X, Orlicky S, Chen Q, Gertler FB, Mendenhall MD, Sicheri F, Pawson T, Tyers M: Multisite phosphorylation of a CDK inhibitor sets a threshold for the onset of DNA replication. Nature 2001, 414:514-521.

19. Koepp DM, Schaefer LK, Ye X, Keyomarsi K, Chu, C, Harper JW, Elledge SJ: Phosphorylation-dependent ubiquitination of cyclin E by the SCFFbw7 ubiquitin ligase. Science 2001, 294:173-177.

20. Winston JT, Koepp DM, Zhu C, Elledge SJ, Harper JW: A family of mammalian F-box proteins. Curr Biol 1999, 9:1180-1182.

21. Cenciarelli C, Chiaur DS, Guardavaccaro D, Parks W, Vidal M, Pagano M: Identification of a family of human F-box proteins. Curr Biol 1999, 9:1177-1179.

22. Moberg KH, Bell DW, Wahrer DC, Haber DA, Harihara, IK: Archipelago regulates Cyclin E levels in Drosophila and is mutated in human cancer cell lines. Nature 2001, 413: 311-316.

23. Schutte M, Hruba, RH, Geradts J, Maynard R, Hilgers W, Rabindra SK, Moskaluk CA, Hahn SA, Schwarte-Waldhoff I, Schmiegel W, Bayli, SB, Ker, SE, Herman JG: Abrogation of the $\mathrm{Rb} / \mathrm{p} 16$ tumor-suppressive pathway in virtually all pancreatic carcinomas. Cancer Res 1997, 57:3126-3130.

24. Hu B, Mitra J, van den Heuvel S, Enders GH: S and G2 phase roles for Cdk2 revealed by inducible expression of a dominant negative mutant in human cells. Mol Cell Biol 2001, 21:2755-2766.

25. Garrett MD, Fattaey A: CDK inhibition and cancer therapy. Curr Opin Genet Dev 1999, 9:104-111. 